Original article

\title{
Onchocerciasis among Women in a Rural Guinea Savannah Ecotype of Nigeria: Social Implications for Control.
}

\author{
Omolade O. Okwa ${ }^{1, *}$, Ojo- Omoniyi A. Olusola ${ }^{2}$ and Ogunrinade. F. Adelani ${ }^{3}$. \\ Received 28 July, 2008 Accepted 30 June, 2009 Published Online 8 October, 2009
}

\begin{abstract}
:
Objectives: The objective of the current study was investigations on the social factors affecting the control of onchocerciasis among women in an endemic savannah community.

Methods: A randomized sampling of households with women above 18 years of age was conducted in a mesoendemic rural community in the Guinea savannah woodland of northern Nigeria. Two hundred and eighty women were selected randomly from fifty households. Structured questionnaires were administered to the women to solicit their socio-demographic indices. Interviews were conducted as a second exploratory approach.

Results: The investigation helped these women to change their erroneous beliefs about onchocerciasis. They now perceive the disease as a grave social problem demanding urgent attention. Thirty women (14.4\%) were infected with onchocercal symptoms ranging from onchodermatitis, nodules and blindness. There was an increasing prevalence of onchocerciasis with advancing age i.e women 51 years of age and above were mainly affected 17 (51\%). Health care utilization was low; only one person $(3.33 \%)$ had ever sought medical help. Farming was the main occupational risk. There was little knowledge regarding onchocerciasis, $60 \%$ of the women did not know the cause and most of the others cited act of God 7 (23.3\%) and a sign of aging $5(16.6 \%)$. There was however impressive knowledge of black flies and their habits. All the women were illiterate Muslims. Most of the affected women were involved in the polygamous relationship (43.3\%). Health education led all of them to believe they needed treatment. Fear of neglect by husbands was the main reason for their desire for seeking treatment.

Conclusion: Targeted health education, making use of visual aids should be directed at illiterate women in endemic areas of onchocerciasis. The social implication of neglect by husbands was observed as a predisposing factor that can enable future compliance to ivermectin treatment of onchocerciasis.
\end{abstract}

Key Words: Compliance, Ivermectin, Nigeria, Onchocerciasis, Women.

\section{INTRODUCTION}

Human onchocerciasis is a parasitic disease caused by a filarial nematode onchocerca volvulus which is transmitted from person to person through the infectious bites of black flies of the genus Simulium breeding in fast- flowing rivers $[1,2]$. It is one of the tropical diseases slated for eradication by the World Health Organization [3]. In Nigeria, an estimated 180 million are at risk, 3.3 million infected and 114, 000 going blind as a result of the disease [2, 4]. In rural communities in Nigeria, the disease is one of the most debilitating and disabling threats to public health and a socio-economic problem of great magnitude [5].

Edungbola et al [6] stated that Nigeria has the largest number of onchocercal victims in the world, accounting for over a third of global prevalence. World Health Organization also maintains that Nigeria has the largest endemicity of this disease in the World. [7, 8] reported on some of the endemic areas of Onchocerciasis in Nigeria, but of all the filarial parasites affecting humans, onchocerciasis has been the least studied in terms of human behavioral and social aspects [9]. Social factors are important in ensuring the efficiency of control programmes [10].

Women in rural communities represent a strategic social category for onchocerciasis control because of their activities as mothers, housekeepers, food producers and processors, carriers of fuel and water as well as their involvement in rural economy which exposes them to contact with

\footnotetext{
Department of Zoology, Faculty of Science, Lagos State University, P. M. B. 001 LASU post office, Nigeria

2 Department of Microbiology, Faculty of Science, Lagos State University, Nigeria

Department of microbiology and parasitology, Faculty of veterinary medicine, University of Ibadan, Ibadan, Nigeria

*Corresponding author:

Department of Zoology, Lagos State University, Lagos, Nigeria

Tel: 234 (01) 08028313362

Email: okwaomolade@hotmail.com, Omolade.Okwa@lasunigeria.org
} 
black flies and disease risk [10].

Traditional African societies are basically patriarchal, and this is reflected in customs, beliefs, and religious practices of the people. Under this system, women receive less attention than they deserve. Consequently, the health status of women, especially in Islamic communities where the 'purdah' system is practiced, may be underestimated [11].

Eco-climatic factors are known to affect onchocerciasis distribution in Nigeria [12]. The forest and savannah strains of onchocerca volvulus exhibit differing characteristic presentations. The forest strain is characterized by severe onchodermatitis while the savannah strain is characterized by blindness [13]. Ivermectin is the current drug of choice for the control of the disease. This microfilaricide can be used on a wide scale for mass treatment of onchocerciasis [14]. The problem in mass treatment programmes is the issue of compliance. Compliance is an important measure of success for disease control at the community level [15]. Greater compliance in community- based treatment programmes can be ensured by women. Women occupy an important position in the domestic domain; they are key agents of change and target groups for any developmental programme [16]. Studies on social demography as well as knowledge, attitudes, beliefs, and practices (KABP), are essential for effective control programmes. Harnessing the participation and contribution of women will have a ripple effect on the community. However, the benefits can only be achieved if women have the right information.

\section{METHODS}

\section{Study Area}

The study was carried out in Koro Village in Borgu Local Government Area of Niger State, Nigeria. The village is located in close proximity to the Kainji Dam, the main source of black flies breeding in the area. The dam is fed by the River Niger. The community was derived from a settlement built in 1960 for those displaced following the construction of the dam.

The area is situated in the Northern Guinea Savannah woodland ecotype of Nigeria. This also falls in the middle belt area of the Country. Temperature is high with a minimum of $20^{\circ} \mathrm{C}$ and maximum of $39^{\circ} \mathrm{C}$. The maximum precipitation is experienced in July-August, and from 11.30am the climate is very hot and tropical. The only health facility in the village is a community dispensary. Houses are built in such a way to as to seclude women in inner rooms.

\section{Study subjects and mobilization}

Public announcements about the current survey were made in the mosques. This was carried out within a week.
The village head called 'Sarki' passed the information to the heads of households, who in turn informed the women. Two hundred and eight women from 145 families within 50 compounds were selected randomly. Each family was represented by selecting one or two women based on the size of the family and informed consent.

\section{Rapid Assessment Procedure (RAP).}

To select women for the actual survey, the manifestations of onchocerciasis was assessed by observation of the exposed body parts of the women i.e. faces, neck, shoulders, arms and legs. Such manifestations as blindness, decreased visual activity, leopard skin and palpable onchocercal nodules were assessed based on the procedure of Murdoch et al [17]. Blindness and decreased visual acuity were assessed by raising two fingers at a distance of $1 \mathrm{~m}$ from the subject. The subject then confirmed seeing the fingers or not.

\section{Administration of Questionnaires}

The structured questionnaire was validated, pre-tested and a pilot survey first carried out. The women were informed about the purpose of the exercise. Only the infected women were administered questionnaires so as to deduce the socio- demographic relationship to the infection. The 30 women were unable to read or write, so the questionnaires were filled out with the help of an interpreter. It took 15-20 minutes to complete each questionnaire.

\section{Interviews.}

This involved a dialogue with each of the 30 infected women and provided an opportunity to ask more than could be included in the questionnaire. It was an interactive process, a second exploratory approach that collected information on various aspects of the life of the women relating to the disease. This allowed for higher response rates.

\section{Health Education:}

After the interview, the women were informed altogether of the need for treatment to avoid or reverse the manifestations. They were also informed that blackflies transmit the disease. The health education was conducted by the authors with the aid of pictures depicting onchocercal victims and blackflies. This shed more light on the disease symptoms, transmission and treatment.

\section{RESULTS}

The socio-demographic profile of the infected women is presented in Table 1. Out of 208 women, 30 (14.4\%) were infected. Two (6.66\%) were blind (B) and also had nodules, 6 (20\%) had palpable onchocercal nodules (PON), 
Table 1: Socio-demographic profile of infected women 30/208 of the population sampled.

\section{Religion No (\%) \\ Muslim 30 (10) \\ Christian 0 (0) \\ Traditional $0(0)$ \\ $D f=1 P<0.05$}

\section{Occupation \\ Housewives 20 (66.6) \\ Farmers 10 (33.3) \\ Traders $0(0)$ \\ Others $0(0)$ \\ $D f=3 P<0.05$}

\section{Education}

Illiterate $30(100)$

Literate $0(0)$

$D f=1 P<0.05$

\section{Have you sought medical help?}

Yes $1(3.33 \%)$

No 29 (96.7)

$D f=1 P=<0.05$

\section{Length of stay in study area}

All my life 26 (86.7)

Long time ago 02 (6.67)

Few years $02(6.67)$

$D f=2 P<0.05$

\section{Clothing (exposure)}

Fully clothed 30 (100)

Half clothed $0(0)$

$D f=1 P<0.05$

\section{Marital Status}

Married 21 (70)

a. Polygamous 13 (43.3)

b. Monogamous 8 (26.7)

Widowed 9 (3)

$D f=2 P<0.05$

${ }^{*} \mathrm{P}<0.05$ Significant, $\mathrm{P}>0.05$ Not Significant
Table 2: Infected women's knowledge and perception of Onchocerciasis and black flies

Knowledge about manifestations No (\%)

Leopard skin 30 (100)

Palpable Nodules 30 (100)

$D f=1 P<0.05$

Knowledge about black flies

Knows black flies 30 (100)

Does not know black flies 0 (0)

$D f=1 P<0.05$

\section{Knowledge about cause of Onchocerciasis}

Act of God 07 (23.3)

Sign of Aging 5 (16.6)

No Comments (don't know) 18 (60)

Black flies $0(0)$

$D f=3 P<0.05$

\section{Knowledge about breeding places of blackflies.}

River 02 (6.7)

No comments (don't know) 28 (93.3)

Garbage $0(0)$

Others $0(0)$

$D f=3 P<0.05$

\section{Effect of blackflies bites}

Itching 27 (90)

Swelling 01 (33)

Both 02 (6.7)

Others $0(0)$

$D f=3 P<0.05$

Actions taken against flies

Kill them 22 (73.3)

Leave them 01 (3.33)

Don't know 07 (23.3)

$D f=2 P<0.05$

\section{Self protection from black flies}

Local insecticides 3 (10)

Fans 1 (3.33)

Fire / Smoke 20 (66.6)

Mats 5 (16.6)

No Comments 1 (3.33)

$D f=4 P<0.05$

${ }^{*}$ The Numbers in parentheses indicate percentage values $\mathrm{P}<0.05$ Significant and $\mathrm{P}>$ 0.05 Not Significant.
$8(26.6 \%)$ had leopard skin (LS), $10(33.3 \%)$ had chronic palpular onchodermatitis (CPOD) and 4 (13.3\%) had acute palpular onchodermatitis (APOD) (See Figure 1). Women aged 51 and above had palpable nodules, leopard skin and blindness. The age distribution with manifestations is shown in Figure 1. Only 1 woman $(3.33 \%)$ with leopard skin had ever sought medical help at the available dispensary. Twenty six $(86.70 \%)$ of the infected women had lived in the area all their lives. There was an increasing prevalence with age, reaching a peak above 51 years in which 17 $(56.6 \%)$ were infected. The women were mainly housewives $20(66.6 \%)$ but the remaining $10(33.3 \%)$ were farm- 


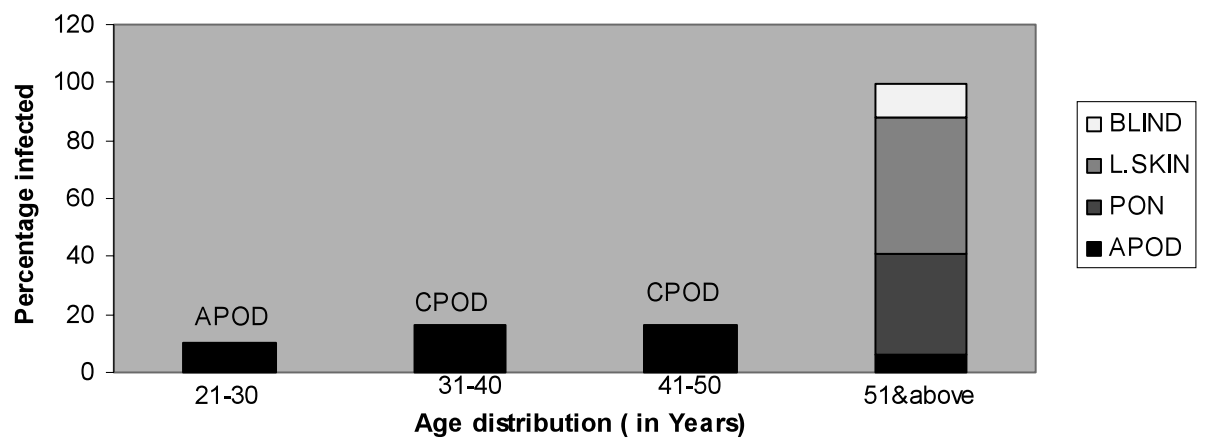

Figure 1. The age distribution of infected women with Onchocercal manifestations.

ers. Although fly bites occurred both indoors and outdoors, more were experienced outdoors. All the women were illiterate Muslims $(100 \%)$. Twenty one $(70 \%)$ were married and $13(43.3 \%)$ were involved in the polygamous relationship. Observation of the level of exposure indicated that the women were all fully clothed at all times $(100 \%)$.

The women's knowledge and perception of onchocerciasis are summarized in Table 2. There was impressive knowledge about the existence of the disease which the women called 'kirichi' (nodule is called ' $g b i$ '). The word 'kirichi' refers to the leopard skin alone. Leopard skin and nodules were seen as unrelated entities. The black fly was well-known and called 'Kusena'. No association was made between the flies and the disease. Twenty seven (90\%) of the women thought that only belief that the flies cause itching and nothing more. Twenty eight (93.3\%) did not know the origin of the flies, $18(60 \%)$ did not know the cause of onchocerciasis while the other women attributed it to an act of God 7 (23.3\%) and a sign of aging 5 (16.6\%).

\section{Response after health information}

The women all agreed that they needed to be treated after receiving health education about the disease and the cause. Many were probably motivated by a desire to be accepted back by their husbands after treatment. The impact of the health education was positive as women were now able to interpret the visual aids correctly. The ability to assess the visual aids correctly was an indication of the positive effects of health education.

\section{DISCUSSION}

The study community is a stable one with few longdistance migrations. This was evident from the movement pattern of the women. The increasing prevalence of onchocerciasis with age is due to repeated fly bites, which indicates the long- term chronicity of onchocerciasis. This also confirms why the women aged 51 and above appeared to have more manifestations. Fly bites found indoors sug- gested that the housewives were never free from fly bites. Occupations such as farming, fishing and domestic activities bring them close to breeding sites which are known to predispose person to more bites [7]. The high illiteracy level of the women implies that health education by print media is not viable here. Demonstrable illustrations, visual aids (pictures) and discussions in local languages are the optimal means to educate these women.

Despite the fact that the women expose very few parts of their bodies to bites by black flies, they were still affected. The level of infected women would have been even higher if hidden body parts were exposed. The reluctance of these women to reveal body parts was due to religious beliefs and shyness.

Many of the women were involved in the polygamous relationship (43.3\%). During the interview, some revealed that their husbands took other wives because of their skin lesions. None of the infected women were newly wedded. Although no divorce was recorded, the women complained of neglect which they also attributed to the skin lesions.

Knowledge, attitudes, beliefs, and practices (KABP) are essential factors when embarking on any drug treatment campaign [9]. This corroborated our findings in this study. As regards Onchocerciasis, the women denied being sick in this study. Okwa [18] reported in a study that women were more concerned about skin diseases than men, while the chief concern among men was decreased economic productivity. Also, in a similar study by Awolola et al [10] on Sabo penguin in same ecotype of Nigeria, people's knowledge and perception of onchocerciasis was just as poor as in the present study. "I don't know" is a common answer from these women. Having no answers to questions is a reflection of the low status of the women, who believed that having answers to questions is a male responsibility. Although these women were familiar with the disease and its vector, there was no recognition of the relationship prior to the health education.

Okwa [19] pointed out the relationship between onchocerciasis transmission and socio-cultural activities. 
These socio-cultural factors could affect future compliance to community- based treatment (COMDT) which is the most favoured control strategy adopted by World Health Organization rather than individual treatment [20]. The factors that can cause non-compliance among women were erroneous or inadequate knowledge of onchocerciasis and its causes, low awareness of the seriousness of onchocerciasis, and perception of the manifestations of onchocerciasis as separate entities. The factors that can enhance future compliance are correction of the belief that onchocerciasis is a social stigma, elimination of neglect of infected women by their husbands leading to unrest in families, and the belief in promotion of the effectiveness of modern medicine.

We advocate that basic amenities like pipe borne water should be provided to reduce physical contact with breeding sites. The use of insecticides accompanied with appropriate health education by visual aids (pictures) is suggested [20]. The women should be allowed to participate in the community directed treatment; there should be good family psychosocial counseling. The Mosques can also be used to inform the community about the implications of avoiding treatment. Women's organizations can also be formed for social support to enhance future compliance in mass drug treatment with Ivermectin.

\section{ACKNOWLEDGEMENT}

This research was funded by a World Health Organization (WHO) grant ID 920032 awarded to Prof. AF Ogunrinade. Special thanks to the Nigeria Institute of Medical Research (NIMR) New Bussa Station, Niger State, Nigeria for field assistance.

Ethical Clearance: Ethical clearance was obtained from ethical committee of the University College Hospital, Ibadan, Nigeria.

\section{REFERENCES}

1 . Tropical disease research. Onchocerciasis: Making health research work for poor people progress report. 2003-2004 UNICEF/ World Bank/WHO.

2 . The Carter center: River blindness control program 2007. Available from: http//www.carter center. Org/health/river blindness/treatment.

3 . Community-directed treatment with ivermectin (CDTI): A practical guide for trainers of community-directed distributors. APOC/WHO. 1998

4 . Hopkins DR Eigege A, Miri ES, Gontor T, Ogah G, Umaru $\mathrm{J}$ et al. Lymphatic filariasis: Elimination and Schistosomiasis control in combination with onchocerciasis control in Nigeria. American Journal of Tropical Medicine and Hygiene 2002; 67 (3); 266-272.
5 . Community-Directed treatment with ivermectin. Report of a multicountry study. UNDP/World Bank/WHO /OCP/ APOC. 1996.

6 . Edungbola LD, Alabi TO, Oni GA, Asaolu SO, Ogunbambo PO, Parakoyi BB. Leopard skin as a rapid diagnostic index for estimating the endemicity of African onchocerciasis. International Journal of Epidemiology 1987; 16 (4): 590-94.

7 . Report of the Director General- World health report; fighting disease fostering development. Geneva WHO 1996; p. 96.

8 . Okwa OO, Awolola TS, Babalola SS and Ogunrinade AF. Onchocerciasis in Nigeria. Nigeria Medical Journal 2001; 40 (2): 41-46.

9 . Okwa OO. Knowledge, attitudes, practices and compliance to ivermectin treatment of onchocerciasis in a rainforest and savannah foci in Nigeria. Nigeria Medical Journal 2000; 39: 78-83.

10. Awolola TS, Manafa OU, Adedoyin JA, Ogunrinade AF, Rotimi OO. Onchocerciasis related beliefs in the Kainji Lake Area: Implications for treatment, prevention and control. Nigeria Quarterly Journal of Hospital Medicine. 2000; 10 (4): 236-238.

11. Okwa OO, Ogunrinade AF. Clinical pattern of Onchocerciasis and health seeking behavior among women living in mesoendemic foci of forest and savannah onchocerciasis in Nigeria. Journal of Prospects in Science 1998; 2: 208-214.

12. Okwa OO. Frequency of onchocerciasis manifestations and health care utilization by women in a rain forest and savannah foci of Nigeria. Research Communications in Parasitology. 2004; 1 (2): 34-42.

13. Ogunrinade AF, Awolola TS, Rotimi O.O, Chandra Shekar R, Weil G. Longitudinal studies of skin microfilariae and antibody conversion rates in children living in an endemic focus of onchocerciasis in Nigeria. ICOPA IX 9th International Congress of Parasitology, Chiba, Japan August 1998; 24-28.

14. Awolola TS, Manafa OU, Rotimi OO and Ogunrinade AF. Knowledge and beliefs about causes, transmission, treatment and control of human onchocerciasis in rural communities in south western Nigeria. Acta Tropica. 2000; 15 (36): 08.

15. Benton B, Bump J, Sekeeti A, Leese B. Partnership and promise. Evolution of the African river blindness campaigns. Annals of Tropical Medicine and Parasitology. 2002; 96: 5-14.

16. Matta S, Khokhar A, Sachdev T.R. Assessment of knowledge about malaria among patients reported with fever. A hospital based study. Journal of vector borne diseases. 2004; 41: 27-31.

17. Murdoch MR, Mackenzie CO, Williams JF, Ghalib WH, Comen S, Abiose B, Jones BR,. A clinical grading system for cutaneous changes in onchocerciasis. Journal of Dermatology. 1993; 129: 260-269.

18. Okwa OO. Onchocerciasis in two communities in Oyo State, Nigeria. Nigeria. Journal of Health and Biomedical Sciences. 20043 (2) 89-92. 
19. Okwa OO. Gender differences in onchocerciasis infection in a rainforest focus of Nigeria. Research Communications in Parasitology 2005; 1 (3): 1-4.

20. Haaland A, Akogun OB, Oladepo O. Community directed implementation of health projects. Reporting with pictures. A concept paper for researchers and health policy decision makers. 1st edition. UNDP/World bank/WHO 2004; 80 pp. 